\title{
DISTRIBUTION OF HEPATITIS C VIRUS GENOTYPES AND SUBTYPES IN CROATIA: 2008-2015
}

\author{
Adriana Vince ${ }^{1,2}$, Snježana Židovec Lepej ${ }^{2}$, Jasna Bingulac-Popović ${ }^{3}$, Manuela Miletić ${ }^{3}$, Sendi Kuret ${ }^{4}$, Sanda \\ Sardelić ${ }^{4}$ Ivana Baća Vrakela², Ivan Kurelac ${ }^{2}$

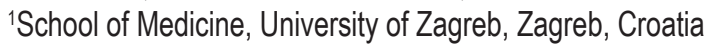 \\ 2University Hospital for Infectious Diseases, Zagreb, Croatia \\ ${ }^{3}$ Croatian Institute of Transfusion Medicine, Zagreb, Croatia \\ ${ }^{4}$ University Hospital Centre Split, Split, Croatia
}

\section{SUMMARY}

Objective: Hepatitis $\mathrm{C}$ virus ( $\mathrm{HCV}$ ) genotyping is an important part of pre-treatment diagnostic algorithms as it guides the choice of therapeutic regimens. The aim of this study was to analyse the distribution of HCV genotypes in patients with chronic hepatitis $\mathrm{C}$ from Croatia in the period 2008-2015.

Methods: The study enrolled 3,655 anti-HCV positive patients with available results of HCV genotyping from the three largest national HCV genotyping laboratories.

Results: The majority of HCV-infected individuals enrolled in the study were male (70.7\%). Analysis of age distribution in a subset of 2,164 individuals showed a mean age of 40.9 years (SD 11.77 years). Croatian patients were mostly infected with HCV genotype $1(56.6 \%)$, followed by genotype $3(37.3 \%)$, genotype $4(4.2 \%)$ and genotype $2(1.8 \%)$. Genotype 1 subtyping in a subset of 1,488 patients showed $54 \%(803 / 1,488)$ of $1 \mathrm{~b}$ infections and $46 \%(685 / 1,488)$ of 1a infections. Percentages of genotype 1 were the highest in Central/Northwestern and Eastern Croatia and the lowest in the Central/Southern Adriatic Region. Genotype 3 was most frequently found in the Central/Southern Adriatic Region (49.1\%) but represented only $17.5 \%$ of infections in Eastern Croatia $(p<0.001)$.

Conclusions: The results of this nine-year retrospective analysis on the distribution of HCV genotypes and subtypes in 3,655 HCV-infected individuals from Croatia showed that the majority of infections can be attributed to genotypes 1 and 3 with absence of major changes in the molecular epidemiology of the two most frequent HCV genotypes infection in Croatia in the past 20 years.

Key words: hepatitis C virus, genotypes, subtypes, Croatia

Address for correspondence: S. Židovec Lepej, Department of Molecular and Immunological Diagnostics, University Hospital for Infectious Diseases "Dr. Fran Mihaljevic", Mirogojska 8, 10000 Zagreb, Croatia. E-mail: Snjezana.Zidovec.Lepej@bfm.hr

https://doi.org/10.21101/cejph.a5021

\section{INTRODUCTION}

Infection with hepatitis $\mathrm{C}$ virus (HCV) is associated with development of liver disease, cirrhosis and hepatocellular carcinoma in a substantial proportion of chronically-infected individuals (1). According to the European Centre for Disease Prevention and Control (ECDC), in 2013 a total of 32,512 cases of hepatitis $\mathrm{C}$ were reported in 26 European Union and European Economic Area (EU/ EEA) Member States, a crude rate of 9.9 per 100,000 population (2).

$\mathrm{HCV}$ is currently classified into 7 genotypes that comprise 67 confirmed subtypes, 20 provisionally assigned subtypes, and 21 unassigned subtypes (3). Additionally, 9 different recombinant forms of HCV have been described so far.

Gower et al. reviewed global HCV genotype distribution by analysing 2,320 studies from 98 countries and showed that genotype 1 accounted for $46 \%$ of HCV infections among adults worldwide ( $22 \%$ attributed to subtype $1 b)$ (4). The estimated distribution of other genotypes was genotype $3(22 \%)$, genotype $2(13 \%)$, genotype $4(13 \%)$, genotype $6(2 \%)$, and genotype 5
(1\%), whereas $3 \%$ of infections corresponded to unknown or recombinant genotypes.

Distribution of HCV genotypes and subtypes is associated with the mode of transmission and it exhibits significant geographic variations on a regional and country level. In Europe, subtype $1 \mathrm{~b}$ and genotypes 2 are usually associated with blood transfusion and unsafe medical procedures whereas subtype 1a and genotype 3 (including subtype 3a) are most commonly found in people who inject drugs, however, many exceptions exist, particularly on a country level (5). Genotype 1 and 3 infections predominate in Europe with subtype $1 \mathrm{~b}$ being the most frequently found subtype in many Central, Western and Eastern European countries with prevalence between 27.2 and $92.6 \%(4,5)$. However, equal prevalence of subtypes $1 \mathrm{a}$ and $1 \mathrm{~b}$ as well as the predominance of subtype 1a was reported for some countries. The prevalence of genotype 4 infections is rising due to the patterns of immigration from non-European areas whereas subtype $2 \mathrm{c}$ and genotype 5 infections are limited to country or local epidemics (5).

$\mathrm{HCV}$ genotyping is an important part of pre-treatment diagnostic algorithms as it guides the choice of therapeutic regimen. Addi- 
tionally, in the era of interferon-free therapy accurate subtyping of HCV genotype 1 (subtype 1a versus $1 \mathrm{~b}$ ) is increasingly important particularly considering HCV resistance to NS5A inhibitors in selected therapeutic regimens (6). The American Association for the Study of Liver Diseases (AASLD) guidelines recommend baseline testing for the presence of NS5A resistance-associated substitutions prior to elbasvir/grazoprevir treatment in patients infected with HCV subtype 1a (7).

Croatia is a small Southeastern European country with a population of more than 4.2 million inhabitants (8). The prevalence of anti-HCV in Croatia is low in many patient groups: $0.5 \%$ in pregnant women, $0.9 \%$ in persons tested as part of diagnostics prior to surgery or in vitro fertilization procedures, and $0.1 \%$ in voluntary blood donors $(5,9,10)$. Higher seroprevalence can be found in sex workers and their clients $(4.0 \%)$, persons with other sexually-transmitted infections $(8.5 \%)$, and men who have sex with men $(2.9 \%)$, but the highest burden of disease can be attributed to intravenous drug users (seroprevalence ranges between $30-65 \%)(5,11,12)$. Treatment of chronic hepatitis C (CHC) based on direct-acting antivirals (DAA) has been available in Croatia since 2015. As of May 2018, interferon-free (IFN-free) treatment options in Croatia include all antivirals approved by the European Medicines Agency except fixed combination of sofosbuvir, velpatasvir and voxilaprevir. According to the 10year retrospective study of 1,163 anti-HCV positive adults in the period between 1996-2005 conducted in the Croatian Reference Centre for Viral Hepatitis, the majority of $\mathrm{HCV}$ infections in Croatia can be attributed to genotypes $1(58.8 \%)$ and $3(35.6 \%)$, whereas genotypes $2(2.2 \%)$ and $4(3.4 \%)$ were rare (13). A total of $37.4 \%$ infections corresponded to subtype $1 \mathrm{~b}$ with only $13.1 \%$ of infections with subtype 1a.

The aim of this study was to analyse the distribution of $\mathrm{HCV}$ genotype in CHC patients in Croatia in the period 2008-2015 collected from the three largest national $\mathrm{HCV}$ genotyping laboratories and to investigate possible regional differences in the prevalence of HCV genotypes in different counties within the country.

\section{MATERIALS AND METHODS}

\section{Patients}

The study enrolled 3,655 anti-HCV positive patients with detectable HCV RNA tested in three largest HCV genotyping laboratories in Croatia: the Croatian Reference Centre for Diagnostics and Treatment of Viral Hepatitis at the University Hospital for Infectious Diseases (UHID) in Zagreb ( $n=1,269$ patients), Croatian Institute of Transfusion Medicine (CITM) in Zagreb ( $n=1,415$ patients), and University Hospital Centre (UHC) in Split $(n=971$ patients). HCV genotyping in all patients was performed at admission to clinical care. The first available patient's HCV RNA positive sample was used for genotyping. Patient's data collected from the three testing sites included age, gender, HCV genotype and/or subtype and county of origin.

\section{Regional Distribution of HCV Genotypes}

The analysis of regional differences in the distribution of $\mathrm{HCV}$ genotypes/subtypes was based on combining results from 21 coun- ties into four geographic regions: Central/Northwestern Region $(\mathrm{n}=1,830$ individuals; 8 counties), Eastern Region ( $\mathrm{n}=183 ; 5$ counties), Northern Adriatic and Lika Region ( $n=235 ; 3$ counties), and Central/Southern Adriatic Region ( $\mathrm{n}=1,285 ; 4$ counties).

\section{Molecular Diagnostics}

In UHID, HCV RNA was quantified by using COBAS AmpliPrep/COBAS TaqMan HCV test (Roche Diagnostic Systems, Branchburg, USA) in the period 2008-2009 and by using Abbott RealTime HCV test (Abbott Molecular Inc., Des Plaines, IL, USA) in the period 2010-2015.

HCV RNA quantification in CITM was performed by using COBAS AmpliPrep/COBAS TaqMan HCV test (Roche Molecular Systems Inc., Branchburg, NJ, USA).

In UHC, COBAS Amplicor Hepatitis C Virus Test, version 2.0 (Roche Diagnostics) was used for qualitative detection of $\mathrm{HCV}$ RNA while COBAS TaqMan HCV test version 2.0 (Roche Molecular Systems Inc., USA) was used for HCV RNA quantification.

Determination of HCV genotypes and subtypes in UHID and CITM was performed by using a standardised reverse hybridisation assay Versant HCV genotype 2.0 Assay (LiPA, Siemens Healthcare Diagnostics, Tarrytown, USA) that allows determination of both HCV genotypes and subtypes. At the UHC testing site, HCV genotyping was performed by using LINEAR ARRAY Hepatitis C Virus genotyping test (Roche Molecular Systems Inc., USA) that detects HCV genotypes only (subtyping was not possible).

\section{Statistical Analysis}

Statistical analysis was performed using SAS (version 6.12, SAS Institute, Cary, North Carolina, USA). D'Agostino-Pearson normality test was used to assess the normality of distribution. Normally distributed variables were described by mean \pm standard deviation, while variables that were not normally distributed were shown as median and interquartile range. For parameters without normal distribution, test of significance between groups was performed using the Mann Whitney test or Kruskal-Wallis test. A p-value of $<0.05$ was considered statistically significant.

\section{RESULTS}

\section{Demographic Data}

The majority of HCV-infected individuals enrolled in the study were male $(2,585 / 3,655 ; 70.7 \%)$ whereas $29.3 \%(1,070 / 3,655)$ individuals were females. Analysis of age distribution in a subset of 2,164 individuals showed a mean age of 40.9 years (SD 11.77 years) (Table 2).

\section{Distribution of HCV Genotypes/Subtypes}

Croatian patients were mostly infected with HCV genotype $1(2,070 / 3,655 ; 56.6 \%)$, followed by genotype $3(1,361 / 3,655$; $37.3 \%)$, genotype $4(154 / 3,655 ; 4.2 \%)$, and genotype $2(67 / 3,655$; $1.8 \%)$. Co-infections were detected in two individuals only (Table 1). 
Table 1. Distribution of HCV genotype and subtypes in Croatia, 2007-2015 $(N=3,655)$

\begin{tabular}{|l|c|c|}
\hline \multirow{2}{*}{ HCV genotype/subtype } & \multicolumn{2}{|c|}{ Patients } \\
\cline { 2 - 3 } & $\mathbf{n}$ & $\%$ \\
\hline Genotype 1 total & 2,070 & 50.6 \\
\hline Genotype 1 & 582 & 15.9 \\
\hline Subtype 1b & 803 & 22.0 \\
\hline Subtype 1a & 685 & 18.7 \\
\hline Genotype 2 total & 67 & 1.8 \\
\hline Genotype 2 & 38 & 1.0 \\
\hline Subtype 2b & 9 & 0.25 \\
\hline Subtype 2a/2c & 20 & 0.55 \\
\hline Genotype 3 total & 1,361 & 37.3 \\
\hline Genotype 3 & 507 & 13.9 \\
\hline Subtype 3a & 854 & 23.4 \\
\hline Genotype 4 total & 154 & 4.2 \\
\hline Genotype 4 & 152 & 4.15 \\
\hline Subtype 4a/4c/4d & 2 & 0.05 \\
\hline Subtypes 1a and 3a & 2 & 0.05 \\
\hline Subtypes 1a and 5a & 1 & 0.03 \\
\hline Total & 3,655 & $*$ \\
\hline$*$ The sum of percentages dos not & & \\
\hline
\end{tabular}

${ }^{*}$ The sum of percentages does not equal 100 due to rounding

Subtypes $1 \mathrm{~b}$ and $1 \mathrm{a}$ were detected in $803(22 \%)$ and 685 $(18.7 \%)$ of total number of patients, respectively.

Due to the limitations of the genotyping assay used in one testing site, subtyping information was available for 1,488 of 2,070 patients infected with genotype 1 . Subtype $1 \mathrm{~b}$ was detected in $54 \%(803 / 1,488)$ and subtype 1a in $46 \%(685 / 1,488)$ of patients with available HCV subtyping data.

Subtypes $2 \mathrm{~b}$ and $2 \mathrm{a} / 2 \mathrm{c}$ were detected in $0.25 \%(9 / 3,655)$ and $0.55 \%(20 / 3,655)$ of the total patient number whereas in $38 / 3,655$ (1\%) subtyping of genotype 2 was not performed.

Subtype 3 a was detected in $854 / 3,655(23.4 \%)$ patients whereas subtyping of genotype 3 was detected in 507/3,655 (13.9\%) of patients.
The dynamics of HCV genotype distribution in the period 2008-2015, analysed in 2,240 HCV infected individuals from two centres (UHID and UHC) is shown in Figure 1. Percentages of genotype 1 were consistently higher compared to genotypes 2-4 throughout the whole eight-year period.

\section{Regional Distribution of HCV Genotypes/Subtypes}

Analysis of data based on four geographic regions showed that individuals from Central/Northwestern Region were significantly older compared to those from Central/Southern Adriatic Region (mean 42.8 vs. 38.7 years of age, $\mathrm{p}<0.001$ ) (Table 2). Percentages of females included in the analysis in the four counties ranged between $23.6 \%$ and $33.5 \%$. Significant differences in the gender distribution for the four counties were also found $(\mathrm{p}<0.001)$ (Table 2).

Significant regional differences in the distribution of $\mathrm{HCV}$ genotypes and subtypes were observed in the study (Table 2, Fig. 2). Percentages of genotype 1 were the highest in Central/ Northwestern and Eastern Croatia (64.7\% and 65\%, respectively) and the lowest in the Central/Southern Adriatic Region (45.8\%, $\mathrm{p}<0.001)$. Genotype 3 was most frequently found in the Central/

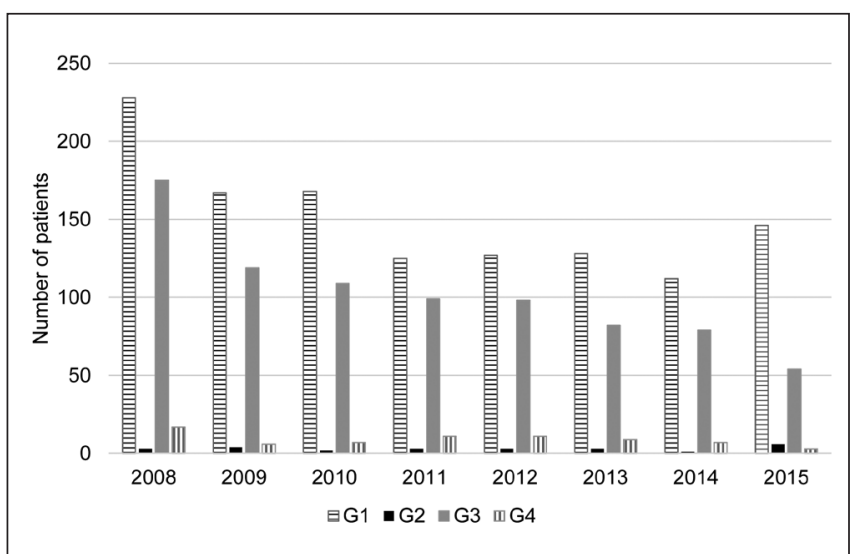

Fig. 1. Dynamics of HCV genotype distribution in 2,240 HCVinfected individuals from two centres in Croatia (UHID and UHC) in the period 2008-2015.

Table 2. Regional distribution of HCV genotypes/subtypes in HCV-infected individuals from Croatia $(N=3,655)$

\begin{tabular}{|c|c|c|c|c|c|}
\hline & $\begin{array}{c}\text { Central and } \\
\text { Northwestern Region }\end{array}$ & Eastern Region & $\begin{array}{l}\text { Northern Adriatic and } \\
\text { Lika Region }\end{array}$ & $\begin{array}{l}\text { Central and South- } \\
\text { ern Adriatic Region }\end{array}$ & $p$-value \\
\hline $\begin{array}{l}\text { Age (years) } \\
\text { Mean (SD) }\end{array}$ & $\begin{array}{c}42.8(12.7) \\
n=1,197\end{array}$ & not available & not available & $\begin{array}{c}38.7(10.0) \\
n=967\end{array}$ & $<0.001$ \\
\hline \multicolumn{6}{|l|}{ Gender } \\
\hline Females & $613(33.5 \%)$ & $51(27.9 \%)$ & $74(31.6 \%)$ & $332(23.6 \%)$ & \multirow{2}{*}{$\begin{array}{c}<0.001 \\
\text { (females vs. males) }\end{array}$} \\
\hline Males & $1,217(66.5 \%)$ & $132(72.1 \%)$ & $161(68.5 \%)$ & $1,073(76.3 \%)$ & \\
\hline \multicolumn{6}{|l|}{ HCV genotype } \\
\hline Genotype 1 & $1,184(64.7 \%)$ & $119(65.0 \%)$ & $126(53.6 \%)$ & $664(45.8 \%)$ & $<0.001$ \\
\hline Genotype 2 & $34(1.9 \%)$ & $2(1.1 \%)$ & $15(6.4 \%)$ & $16(1.1 \%)$ & $<0.001$ \\
\hline Genotype 3 & $554(30.3 \%)$ & $32(17.5 \%)$ & $84(35.7 \%)$ & $691(49.1 \%)$ & $<0.001$ \\
\hline Genotype 4 & $58(3.2 \%)$ & $30(16.4 \%)$ & $10(4.3 \%)$ & $56(4.0 \%)$ & $<0.001$ \\
\hline
\end{tabular}




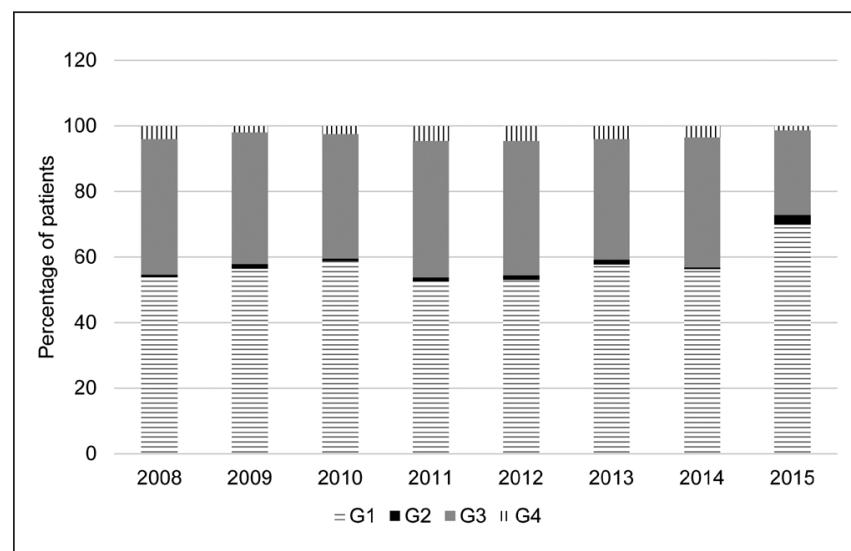

Fig. 2. Dynamics of proportion of particular HCV genotypes in 2,240 HCV-infected individuals from two centres in Croatia (UHID and UHC) in the period 2008-2015.

Southern Adriatic Region (49.1\%) but represented only $17.5 \%$ of infections in Eastern Croatia $(p<0.001)$. Higher percentage of genotype 4 infections was found in Eastern Croatia compared to other regions (Table 2).

Significantly higher percentages of genotype 2 (6.4\%) were observed in Northern Adriatic and Lika Region compared to the other three regions (1.1 and 1.9\%, respectively; $\mathrm{p}<0.001$ ).

\section{DISCUSSION}

The results of this nine-year retrospective analysis on the distribution of HCV genotypes and subtypes in 3,655 HCV-infected individuals from Croatia showed that the majority of infections can be attributed to genotypes 1 and 3 .

The comparison of HCV genotypes 1 and 3 distribution previously described by our group (Vince et al.) in the period 1996-2005 and the current study for the period 2007-2015 ( $58.8 \%$ vs. $56.6 \%$ and $35.6 \%$ vs. $37.2 \%$, respectively) shows the absence of major changes in the molecular epidemiology of the two most frequent HCV genotypes infection in Croatia in the past 20 years (13).

Significant predominance of subtype $1 \mathrm{~b}$ compared to subtype 1a (37.4\% vs. $13.1 \%)$ that was observed in the study by Vince et al. (13) was not confirmed in the current study. However, when comparing the two studies important methodological improvements in HCV subtyping molecular tools should be taken into account. The results by Vince et al. were based on the use of first-generation line-probe molecular assay INNO-LiPA HCV 1.0 that targeted 5' non-coding region of HCV genome. Chevaliez et al. showed that INNO-LiPA HCV 1.0 failed to correctly identify HCV subtype $1 \mathrm{a}$ in $29.5 \%$ and subtype $1 \mathrm{~b}$ in $8.7 \%$ of samples (14). Second generation assay INNO-LiPA HCV 2.0 that targets 5' non-coding and core regions of $\mathrm{HCV}$ genome correctly classified $97.5 \%$ of subtype $1 \mathrm{a}$ and $96.2 \%$ of subtype $1 \mathrm{~b}$ strains (14). Since the subtyping data analysed in the current study was mainly based on the second-generation line-probe assay, direct comparison with Vince et al. was not possible (13).

The absence of significant differences in the proportions of subtype 1a vs. $1 \mathrm{~b}$ HCV infections in Croatia is also clinically relevant when evaluating diagnostic and treatment strategies as well as expected outcomes of CHC treatment with DAA on a national level. Registrations studies for various IFN-free regimens have shown lower sustained virological response (SVR) rates for subtype 1a versus subtype $1 \mathrm{~b}$ infections in selected patient groups (6). Additionally, pre-treatment diagnostic assays recommended for subtype 1a infected individuals (for example analysis of primary NS5A resistance when considering elbasvir/grazoprevir treatment) should be considered as well $(6,7)$. Therefore, the ratio between subtype $1 \mathrm{a}$ and $1 \mathrm{~b}$ infections needs to be carefully evaluated when considering national treatment strategies.

Earlier analysis of regional differences in the distribution of $\mathrm{HCV}$ genotypes revealed similar percentages of subtypes $3 \mathrm{a}$ and $1 \mathrm{~b}$ in the Split region while the majority of infections in the other regions were caused by subtype $1 \mathrm{~b}$ (13). The results of the present study showed that genotype 1 infections predominate in the three geographic regions. However, in the Central and Southern Adriatic Region genotype 3 is more frequently found compared with genotype 1 .

The results of this study also confirmed the earlier observation of the moderate contribution of $\mathrm{HCV}$ genotypes 2 and 4 to the molecular epidemiology of HCV in Croatia (1.8\% and $4.2 \%$, respectively). However, the current study showed for the first time significantly higher percentages of genotype 4 infections in the Eastern Region and genotype 2 infections in the Northern Adriatic and Lika Region compared to other geographic regions in Croatia.

Comparison of our results with the data on the molecular epidemiology of HCV infection in neighbouring countries showed similarities with the Slovenian cohort of HCV-infected patients. Seme et al. analysed 2,776 anti-HCV positive patients newly diagnosed in Slovenia over a 15-year period (1993-2007) and showed the predominance of genotype 1 infections (56\%) followed by genotypes 3, 2 and 4 (with a prevalence of $37.8 \%, 5 \%$, and $1.2 \%$, respectively) (15).

A study on 164 persons with chronic hepatitis $\mathrm{C}$ from Serbia and Montenegro showed the high prevalence of genotype 1 $(57.9 \%)$ that could be attributed almost exclusively to subtype $1 \mathrm{~b}$ infection (54.9\%). Subtype 1a was detected in only one patient $(0.6 \%)$ demonstrating an important difference in comparison with the Croatian data, probably due to the small number of studied patients (16).

Similarly, a small study on the HCV genotype distribution in patients with $\mathrm{CHC}(\mathrm{n}=75)$ and $\mathrm{HCV}$-infected first-time blood donors $(n=13)$ in Northwestern Bosnia and Herzegovina showed the predominance of subtype $1 \mathrm{~b}$ infection $(69.3 \%$ in $\mathrm{CHC}$ patients (17).

In Hungary, subtype $1 \mathrm{~b}$ is highly represented with estimates ranging between $54.4 \%$ to $85.5 \%$ (Cornberg et al.) (18). Contrary to the data from Croatia and Slovenia, a study on $118 \mathrm{HCV}$ infected patients from Hungary showed exceptionally high proportion of genotype 1 infections $(94.1 \%)$ with very low percentages of other genotypes (genotype $2-0.8 \%$, genotype $3-3.4 \%$ and genotype $4-1.7 \%$ ) (19).

A study by Maracsio et al. from Southern Italy that included 2,153 patients with $\mathrm{CHC}$ analysed in the period 2001-2011 showed the predominance of subtype $1 \mathrm{~b}$ followed by subtypes $2 \mathrm{a} / 2 \mathrm{c}$, genotype 3 and 4 (20). The results of the study are consistent with previous studies from various regions confirming the predominance of subtype $1 \mathrm{~b}$ in Italy (1). Subtype $2 \mathrm{c}$ is commonly 
found in the South of Italy whereas it is quite rare in Croatia and its neighbouring countries.

These data clearly demonstrate a high degree of HCV molecular diversity on a national and regional level indicating the need for continuous surveillance of HCV molecular epidemiology.

\section{CONCLUSIONS}

The results of this retrospective nine-year study show that the majority of $\mathrm{HCV}$ infection in Croatia can be attributed to genotypes 1 and 3 and that no major changes in the molecular epidemiology of $\mathrm{HCV}$ infection in the country have been observed for the past 20 years.

\section{Conflict of Interests}

None declared

\section{REFERENCES}

1. Westbrook RH, Dusheiko G. Natural history of hepatitis C. J Hepatol. 2014;61 Suppl 1:S58-68.

2. European Centre for Disease Prevention and Control. Hepatitis C surveillance in Europe - 2013. Stockholm: ECDC; 2015.

3. Smith DB, Bukh J, Kuiken C, Muerhoff AS, Rice CM, Stapleton JT, et al. Expanded classification of hepatitis $\mathrm{C}$ virus into 7 genotypes and 67 subtypes: updated criteria and genotype assignment web resource. Hepatology. 2014;59(1):318-27.

4. Gower E, Estes C, Blach S, Razavi-Shearer K, Razavi H. Global epidemiology and genotype distribution of the hepatitis $\mathrm{C}$ virus infection. J Hepatol. 2014;61 Suppl 1:S45-57.

5. Vilibic-Cavlek T, Kucinar J, Kaic B, Vilibic M, Pandak N, Barbic L, et al. Epidemiology of hepatitis C in Croatia in the European context. World J Gastroenterol. 2015;21(32):9476-93.

6. European Association for the Study of the Liver. EASL Recommendations on treatment of hepatitis C 2018. J Hepatol. 2018:69(2):461-511.

7. American Association for the Study of Liver Diseases, Infection Diseases Society of America. Recommendations for testing, managing, and treating hepatitis C [Internet]. AASD; c2014-2018 [cited 2018 Aug 23]. Available from: http://www.hcvguidelines.org.

8. Population according to nationality- detailed classification- the 2011 census [Internet]. Zagreb: Croatian Bureau of Statistics [cited 2016 Jun
10]. Available from: http://www.dzs.hr/Hrv/censuses/census2011/results/ htm/H01_01_05/H01_01_05.html. (In Croatian.)

9. Kaić B, Vilibić-Cavlek T, Filipović SK, Nemeth-Blazić T, Pem-Novosel I, Vucina VV, et al. Epidemiology of viral hepatitis. Acta Med Croatica. 2013;67(4):273-9. (In Croatian.)

10. Vilibić-Čavlek T, Kučinar J, Ljubin-Sternak S, Kaić B, Lazarić-Stefanović $\mathrm{L}$, Kolarić B, et al. Prevalence of viral hepatitis in Croatian adult population undergoing routine check-up, 2010-2011. Cent Eur J Public Health. 2014;22(1):29-33.

11. Čavlek TV, Margan IG, Lepej SZ, Kolarić B, Vince A. Seroprevalence, risk factors, and hepatitis $\mathrm{C}$ virus genotypes in groups with high-risk sexual behavior in Croatia. J Med Virol. 2009;81(8):1348-53.

12. Vilibić Čavlek T, Marić J, Katičić Lj, Kolarić B. Hepatitis C virus antibody status, sociodemographic characteristics, and risk behaviour among injecting drug users in Croatia. Cent Eur J Public Health. 2011;19(1):26-9.

13. Vince A, Iscić-Bes J, Zidovec Lepej S, Baća-Vrakela I, Bradarić N, Kurelac I, et al. Distribution of hepatitis C virus genotypes in Croatia-a 10 year retrospective study of four geographic regions. Coll Antropol. 2006;30 Suppl 2:139-43.

14. Chevaliez S, Bouvier-Alias M, Brillet R, Pawlotsky JM. Hepatitis C virus (HCV) genotype 1 subtype identification in new HCV drug development and future clinical practice. PLoS One. 2009 Dec 8;4(12):e8209. doi: 10.1371/journal.pone.0008209.

15. Seme K, Vrhovac M, Mocilnik T, Maticic M, Lesnicar G, Baklan Z, et al. Hepatitis C virus genotypes in 1,504 patients in Slovenia, 1993-2007. J Med Virol. 2009;81(4):634-9.

16. Svirtlih N, Delic D, Simonovic J, Jevtovic D, Dokic L, Gvozdenovic E, et al. Hepatitis $\mathrm{C}$ virus genotypes in Serbia and Montenegro: the prevalence and clinical significance. World J Gastroenterol. 2007;13(3):355-60.

17. Ahmetagic S, N Salkić N, Cickusic E, Zerem E, Mott-Divković S, Tihic $\mathrm{N}$, et al. Hepatitis $\mathrm{C}$ virus genotypes in chronic hepatitis $\mathrm{C}$ patients and in first time blood donors in northeastern Bosnia and Herzegovina. Bosn J Basic Med Sci. 2009;9(4):278-82.

18. Cornberg M, Razavi HA, Alberti A, Bernasconi E, Buti M, Cooper C, et al. A systematic review of hepatitis $\mathrm{C}$ virus epidemiology in Europe, Canada and Israel. Liver Int. 2011;31 Suppl. 2:30-60.

19. Sarvari C, Ujhelyi E, Szlavik J. Determination of hepatitis C virus genotypes in Hungary using the Trugene HCV 3 'NC genotyping test. ISMD2010 Eight International Symposium on Molecular Diagnostics 2010 Graz, Austria. Clin Chem Lab Med. 2010;48(5):A1.

20. Marascio N, Matera G, Quirino A, Giancotti A, Barreca GS, Lamberti $\mathrm{AG}$, et al. Eleven-year distribution pattern of hepatitis $\mathrm{C}$ virus in southern Italy. J Pathog. 2012;2012:631095. doi: 10.1155/2012/631095.

Received December 28, 2016 Accepted in revised form August 23, 2018 